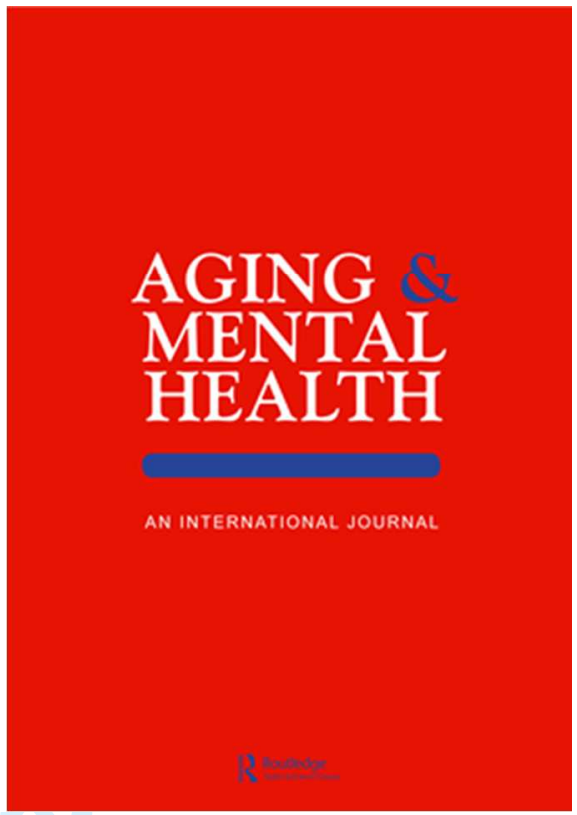

\title{
Consensus Statement of the International Summit on Intellectual Disability and Dementia Related to Post- Diagnostic Support
}

\begin{tabular}{|r|l|}
\hline Journal: & Aging and Mental Health \\
\hline Manuscript ID & CAMH-2017-0237.R1 \\
\hline Manuscript Type: & Original Article \\
\hline Keywords: & $\begin{array}{l}\text { consensus statement, dementia, Intellectual Disability < Other Psychiatric } \\
\text { Disorders, non-pharmacological interventions, post-diagnostic support }\end{array}$ \\
\hline \multicolumn{2}{|l}{} \\
\hline
\end{tabular}

\section{SCHOLARONE ${ }^{m}$ \\ Manuscripts}

The Version of Record of this manuscript has been published and is available in http://www.tandfonline.com/10.1080/13607863.2017.1373065 


\section{Consensus Statement of the International Summit on Intellectual Disability and Dementia Related to Post-Diagnostic Support ${ }^{1}$}

Key words: consensus statement, dementia, intellectual disability, non-pharmacological interventions, post-diagnostic support

\section{Authors:}

Karen Dodd ${ }^{1}$, Karen Watchman ${ }^{2}$, Matthew P. Janicki ${ }^{3}$, Antonia Coppus ${ }^{4,5}$, Claudia Gaertner ${ }^{6}$, Juan Fortea ${ }^{7,8}$, Flavia H. Santos ${ }^{9,10}$, Seth M. Keller ${ }^{11}$, Andre Strydom ${ }^{12}$

${ }^{1}$ Surrey and Borders Partnership NHS Foundation Trust, Leatherhead, UK

${ }^{2}$ University of Stirling, Scotland

${ }^{3}$ University of Illinois at Chicago, USA

${ }^{4}$ Radboudumc, Nijmegen, The Netherlands

${ }^{5}$ Dichterbij Centre of the Intellectual Disabled, Gennep, The Netherlands

${ }^{6}$ Theodor Fliedner Foundation, Muelheim an der Ruhr, Germany

${ }^{7}$ Hospital de la Santa Creu i Sant Pau--Biomedical Research Institute Sant Pau, Barcelona, Spain

${ }^{8}$ Down Medical Center, Fundació Catalana Síndrome de Down, Barcelona, Spain

${ }^{9}$ University of Minho, Braga, Portugal

${ }^{10}$ UNESP - São Paulo State University, Bauru, Brazil

${ }^{11}$ Advocare Neurology South Jersey, Lumberton, NJ USA

12 University College London, UK

Author correspondence address:

Dr Karen Dodd

Co-Director of Services for People with Learning Disabilities

Surrey and Borders Partnership NHS Foundation Trust

Leatherhead Hub

18 Mole Business Park

Leatherhead KT22 7AD United Kingdom

Tel: +4401372 216004 or +4401372 205767

email: Drkaren.Dodd@sabp.nhs.uk

\footnotetext{
1 This consensus statement was developed as an output from the 2016 International Summit on Intellectual Disability and Dementia, held in Glasgow, Scotland, 13-14 October 2016, and hosted by the University of Stirling and University of the West of Scotland, funded by the RS MacDonald Trust, the Scottish Government, and Alzheimer Scotland. Collaborating sponsors included the National Task Group on Intellectual Disabilities and Dementia Practices (NTG) in the United States and the University of Illinois at Chicago. The Summit was composed of individuals and representatives of many international and national organizations with a stake in issues related to adults with intellectual disability affected by dementia. The contents of this statement were partially developed under a grant from the United States Department of Health and Human Services, Administration for Community Living (ACL), National Institute on Disability, Independent Living, and Rehabilitation Research (NIDILRR) Grant \# 90RT5020-03-00. However, those contents do not necessarily represent the policy of the US Department of Health and Human Services, nor the endorsement by the US Federal Government. The opinions expressed represent those of the Summit participants and of the NTG.
} 
Consensus Statement of the International Summit on Intellectual Disability and Dementia Related to Post-Diagnostic Support

Key words: consensus statement, dementia, intellectual disability, non-pharmacological interventions, post-diagnostic support

\begin{abstract}
Objectives: Post diagnostic support (PDS) has varied definitions within mainstream dementia services and different health and social care organizations, encompassing a range of supports that are offered to adults once diagnosed with dementia until death.

\section{Method:}

An international summit on intellectual disability and dementia held in Glasgow, Scotland in 2016 identified how PDS applies to adults with an intellectual disability and dementia. The Summit proposed a model that encompassed seven focal areas: post-diagnostic counseling; psychological and medical surveillance; periodic reviews and adjustments to the dementia care plan; early identification of behaviour and psychological symptoms; reviews of care practices and supports for advanced dementia and end of life; supports to carers/ support staff; and evaluation of quality of life. It also explored current practices in providing PDS in intellectual disability services.
\end{abstract}

Results: The Summit concluded that although there is limited research evidence for pharmacological or non-pharmacological interventions for people with intellectual disability and dementia, viable resources and guidelines describe practical approaches drawn from clinical practice. Post diagnostic support is essential, and the model components in place for the general population, and proposed here for use within the intellectual disability field, need to be individualized and adapted to the person's needs as dementia progresses.

Conclusions: Recommendations for future research include examining the prevalence and nature of behavioral and psychological symptoms (BPSD) in adults with an intellectual disability who develop dementia, the effectiveness of different non-pharmacological interventions, the interaction between pharmacological and non-pharmacological interventions, and the utility of different models of support. 


\section{Introduction}

Post diagnostic support (PDS) has varied definitions within mainstream dementia services and in use by a range of health and social care oriented organizations. The World Health Organization (WHO, 2012) in Dementia, A Public Health Priority, noted that PDS was a component of long term care, along with community services and continuing care. The WHO defines PDS as "planning for the future; offering support, advice and information as needed, and helping maintain independence (p.51)." The Report also defined community services as "helping people with dementia to remain at home as long as they wish and until it is no longer possible, and providing short breaks / respite care to support [carers] and providing an opportunity for social engagement for the recipient". Continuing care was defined as "caring for people who can no longer stay at home (e.g. in different kinds of supported or institutional living arrangements such as group homes and residential care), and providing support for the end stages of dementia.

Other organizations have taken a different perspective and define PDS as generally encompassing all activities following diagnosis. Using a conceptual perspective, Alzheimer Scotland (2011) published a model built upon five "pillars" to help explain the range of services considered useful in post-diagnostic support. The pillars are (a) supporting community connections (supports to maintain and develop social networks); (b) peer support (derived from other people with dementia, their families, and carers - to help come to terms with having dementia and maintain well-being and resilience); (c) planning for future care (supports, when they are ready, to plan the shape of their future care from their own perspective together with those around them, developing a personal plan with their choices, hopes, and aspirations which can guide professionals), (d) understanding the illness and managing the symptoms (support to come to terms with dementia and learn about selfmanagement of the condition); and (e) planning for future decision making including addressing other legal issues, such as setting up 'powers of attorney'.

Using a psychological perspective, Watts, Cheston, \& Moniz-Cook, (2013) suggested a model that includes a series of supports, including psychosocial interventions based on the needs 
and preferences of the person with dementia and, where appropriate, his or her carer; giving attention to the cognitive and emotional aspects of dementia; addressing complex needs through various means; providing psychosocial interventions for carers of people with dementia; ensuring that staff delivering psychosocial interventions are appropriately trained and supervised; and obtaining feedback on the efficacy of the interventions. The British Psychological Society Dementia Advisory Group (British Psychological Society, 2016) emphasised the importance of focusing care and support on the person rather than the disease, leading to an emphasis on what helps people to live well with dementia. They recommend that people have the knowledge of where to get what they need; a sense of belonging and being valued by their family and community; opportunity to participate in meaningful activities, and be part of a local dementia friendly and supportive community; have support that enables people to live a full life including the use of life stories, evidence based psychological interventions and strategies for maintaining or improving a person's skills, interests and activities; and, live in an enabling and supportive environment.

Others have noted that PDS needs to employ varied components to be effective. The components might include (a) conveyance of information to the person diagnosed with dementia, as well to his or her potential carers (Abley et al., 2013; Prince, Comas-Herrera, Knapp, Guerchet, \& Karagiannidou, 2016); (b) stimulating and aiding in advance care planning (Dening, King, Jones, Vickestaff, \& Sampson, 2016); (c) continual and multi-layered interventions and care supports (Backhouse, Dickens, Richards, McCabe, 2015); (d) interventions which are directed at reducing carer burden and supports for carers in developing appropriate coping strategies (Dawson, Bowes, Kelly, Velzke, \& Ward, 2015; WHO, 2015); (e) for some, self-directed care, including adoption of 'advance directives' or 'advance decisions' for future care (Dawson et al., 2015; Health Quality Ontario, 2008); and (f) mitigating behavioural crises (Kales, Gitlin, \& Lyketsos, 2015). It has been proposed that the main objective of PDS is to enable people with dementia to continue living in the community with a good quality of life, provide information and support, support people in dealing with issues arising from receiving a diagnosis, and delay potential admission to longterm residential care (Szymczynska, Innes, Forrest, \& Stark, 2010). In summing up a critical review of PDS, Dawson et al., (2015), noted that "the best outcomes for people with 
dementia are associated with services that are timely, responsive, flexible, and tailored to individual need."

With respect to timelines, initially, PDS referred to the period after diagnosis and through the first year (consistent with the WHO, 2012, perspective). However, increasingly PDS is being referred to as appropriate post diagnostic care throughout the rest of the person's life (Department of Health 2016). This timeline also recognizes the changing demands that evolving dementia presents to people, and that PDS in turn changes in focus with progression. Therefore, any definition needs to be sufficiently fluid to accommodate varied interventions and approaches defined by both the stage of dementia and the needs of the person with dementia. This notion has therefore led to varying perceptions and models of PDS.

An issue discussed at the International Summit ${ }^{1}$ was 'To what degree and intent does PDS with respect to people with intellectual disability mirror these generic models and practices?' For the most part, there is general agreement that within services for people with intellectual disability, PDS is aimed toward the person with dementia, their families, their friends, and their support staff. The support may be through specific nonpharmacological and / or pharmacological approaches and through specialised care practices.

The aim of this Summit statement is to explore how PDS for persons with intellectual disability corresponds or differs from applications in the general population, and what are the critical components that should make up PDS when applied to people with intellectual disability.

The rationale for a consensus statement is based on the need to formalize the sequencing of service provision following both suspected and then diagnosis of dementia. People with

\footnotetext{
${ }^{1}$ The 33 Summit participants represented a number of disability, aging, and dementia national and international organizations, academic institutions, government officials, and family members, had diverse professional backgrounds, and came from some 15 countries in Europe and North and South America.
} 
intellectual disabilities are experiencing increasing life expectancy and reduced morbidity, and with this, susceptibility to the same neuropathologies as for people in the general population. The exception to this is people with Down syndrome, where there is well documented significant elevated risk of developing Alzheimer's disease. The summit recognized that there is a need for a statement that can focus attention on PDS processes and services as well as stimulating the research agenda and produce new approaches to public health policy for people with intellectual disabilities and dementia.

In summary, the literature highlights that approaches in the general population and for people with an intellectual disability typically run in parallel, with the exception that in many situations the PDS services that are made available to people with intellectual disability tend to be extensions of clinical services that are provided prior to dementia, which are then then adapted to the specifics of dementia. This is covered in detail in the Approaches section below.

\section{PDS Model with Application to Intellectual Disability}

The Summit explored what might comprise a working model of PDS that could be applied to people with intellectual disability and dementia and their carers/ support staff. Firstly, the proposed model's assumption is that the timeline for PDS is from the point where the diagnosis is highly suspected to when the person reaches the end of life stage of dementia. End of life issues are considered in a separate publication from the Summit (McCallion et al., 2017). Secondly, the model supposes that in concert with national dementia care policies, family, ethnic and cultural values, and the preferences of the adult, provision of PDS is within a community-based framework. It is therefore designed to preclude inappropriate change of accommodation or day services. The components of the proposed model include:

- $\quad$ Post-diagnostic counselling/ support and education is offered to the person and carers/ support staff to help empower them to deal with the condition in the most optimal way related to the diagnosis, its implications, and the probable course/trajectory. 
- Psychological and medical surveillance is carried out throughout the course of decline to address dementia-related needs and conditions (e.g. epilepsy) and nondementia comorbid conditions, irrespective of whether they impact directly on the course of dementia.

- $\quad$ Periodic, but regular and planned, reviews are undertaken of the person's program / care plan to identify significant changes in health, function and quality of life, and adjustments are made in activities and care practices to ensure that the person continues to receive quality person-centred care.

- $\quad$ Early Identification of behavioural and psychological symptoms of dementia occurs and reviews of care practices and supports are undertaken when such symptoms are present.

- $\quad$ Reviews are undertaken of care practices and supports provided when advanced dementia is reached and when the condition of the individual changes and there is a presumption of approaching death.

- Supports are offered to carers/ support staff throughout the course of the condition, from both specialist and mainstream services, and there is a continuing provision of information.

- Quality of life is evaluated at regular intervals from both the perspective of the person with intellectual disability and carers/ staff, across the course of the person's journey.

These components are necessary across all stages of dementia, although some are more pertinent to specific stages. However, it is recognised that excellence in dementia care is facilitated by thorough and detailed future planning, so that professionals, carers, and paid staff are cognisant of future issues that will arise and have planned for them (e.g. for advanced dementia and end of life).

\section{Approaches}


The Summit arrived at consensus in principle that PDS is integral and essential for people with intellectual disabilities who develop dementia. It was acknowledged that most prescriptive work with respect to intellectual disability and PDS generally should follow that of the precepts for PDS in the general dementia care field. However, in many situations, services for people with intellectual disability are often more focused on taking a personcentred approach to care and support than those in the general dementia field. It was clear that there are differences in policies and practices in different countries with respect to what constitutes the post-diagnostic period. The Summit agreed that PDS has sequential and concurrent features, including what happens early in the post-diagnostic period, what follows in general with care directed toward mitigating progressive decline, and how ancillary features are supported and augmented. The Summit also recognized the benefits of both non-pharmacology and pharmacological approaches to PDS.

In many economically developed nations where the state funds health and/or welfare services, and who have across the world with explicit public policy enabling lifelong support services for people with an intellectual disability, adults who develop dementia are usually known to formal services. PDS is therefore generally aimed at adapting what is already known about and in place for them to meet this added need. This may entail accessing additional supports both for the person and the people supporting him or her at social, emotional, and behavioural levels, as well as using specific interventions that have been adapted to accommodate the person's degree of intellectual disability (Tiziano et al., 2017). It is generally recognized that levels of function, language skills, and self-direction will define what interventions may be most useful. From an evidence-based perspective, as there is not yet a large body of research on the efficacy of specific interventions or approaches, most of the knowledge in this area is drawn from clinical practice or consensus among knowledgeable workers and organizations (BPS, 2015; Dodd, Bush, \& Livesey, 2015; Jokinen et al., 2013).

In other countries, or in situations where the adult may have never been part of intellectual disability specialty services, this may be handled differently. At the point of diagnosis, 
recognition that dementia is present may begin the introduction of supports that may be similar to those provided to other people with dementia, but the process may lack formality and be offered on an ad hoc basis. Brazilian public policy, for example, supports adults with Down syndrome typically living with their families; rather than being in residential or long term supported living, or institutional care (Fonseca, de Oliveira, de Figueiredo Ferreira Guilhoto, Cavalheiro, \& Bottino, 2014). Voluntary carers, usually parents or siblings and at times a neighbour or friend, prevail over professional carers. In such situations, it is common for family members, despite often aging or at times having other caring commitments themselves, to become carers due to the fear that the person with intellectual disability might be neglected in an institution (Carvalho, Ardore, \& Castro, 2015). However, if support has not been typically accessed or required until this point, the changes in their family member can prove challenging for the family and at times result in a breakdown in living arrangements. This places the person with intellectual disability at increased risk of a crisis rather than planned move, often with associated behavioural changes due to a new and strange environment with different carers or admission to a long-term care facility (Carvalho et al., 2015; Courtenay, Jokinen, \& Strydom, 2010).

It is the Summit's position that irrespective of the nature and extent of existing public policies or services available within a country, special efforts be made to aid the family or other carers to have an understanding of dementia and its consequences, as well as to offer information, aid, and supports for extended caregiving, and provide relief for caregiving when indicated. Such PDS-related activities can be undertaken via formal initiatives or via informal efforts of non-governmental organizations, parent associations, or by neighbors and friends. For those nations with undeveloped market economies and low levels of investment in health and welfare services where there is an absence of focus on dementia supports for people in general, and for people with intellectual disability in particular, this Consensus statement can be adopted and used to help develop the required supports in the future.

\section{Non-pharmacological approaches}


Non-pharmacological approaches have been shown to be useful, versatile, and costeffective in improving outcomes and quality of life among adults with dementia (Olazaran et al., 2010). These approaches should also enhance the quality of life of persons with intellectual disability affected by dementia, and should be used in combination as needed for each person, and be able to demonstrate effectiveness (Dodd et al., 2015; Gitlin, Kales, \& Lyketsos, 2012). All approaches and practices should be subject to periodic and regular review as outlined in our model of the components of PDS.

Early phase PDS and intellectual disability. PDS should start with sharing the diagnosis of dementia with the person with intellectual disability wherever possible; although there are differing opinions about the utility of doing this (BPS 2015; Tuffrey-Wijne \& Watchman, 2014). The presentation of information and how it is delivered will be a function of the innate capacity of the adult to integrate the information and how cognitively affected he or she may be by dementia. Many professionals believe that an individualised person-centred approach to deciding how much information to share with the person with intellectual disability and their carers and support staff is key to enabling adaptation and understanding of what the person, their carers and support staff are experiencing and will continue to experience. This will enable adults to better understand and cope with their changing experiences (Tuffrey-Wijne \& Watchman, 2014; Watchman, 2012). This approach also helps to ensure that the person is involved as much as possible in decisions about support and care, and is supported in describing and recording his or her views and preferences about future care. Technical aids that can build capability among carers / support staff have been developed and can be used with people, carers and support staff, such as "The Journey of Life, About My Friend and About Dementia" (Dodd, Turk, \& Christmas, 2005 a -c), "What is Dementia?" (Kerr \& Innes, 2000), and "Jenny's Diary" (Watchman, Tuffrey-Wijne, \& Quinn, 2015) in the UK, "Guidelines for Structuring Community Care and Supports for People with Intellectual Disabilities Affected by Dementia“ (Jokinen et al., 2013) in the USA, "Menschen mit Demenz und geistiger Behinderung begleiten- eine Handreichung für Mitarbeitende der Behinderten- und Altenhilfe" (Demenz-Service NRW, 2016) in Germany, and "Dementie bij mensen met een verstandelijke handicap: brochure voor verwanten en professionele ondersteuners" (Maaskant \& Schuurman, 2012) in the Netherlands. 
Psychological and non-pharmacological approaches for people with intellectual disability and dementia need to be delivered in line with a clear conceptual framework of dementia that aids staff in understanding what is happening to the person with dementia and the effect of their care and responses (BPS, 2015). Current guidelines for the management of behavioral and psychological symptoms of dementia in the general population include those from the UK National Institute for Health and Care Excellence (NICE, 2012), the American Psychiatric Association (2013), the International Psychogeriatric Association (2015), the German Association for Psychiatry, Psychotherapy and Psychosomatics (DGPPN, 2016), the Dutch Society for Clinical Geriatrics (Nederlandse Vereniging voor Klinische Geriatrie, 2014) and the American Geriatrics Society (2013). With respect to PDS, these guidelines recommend the use of non-pharmacologic behavioral strategies at first for behavioural problems, but do not present any evidence base for these approaches or give weight to the evidence for one non-pharmacologic approach over another (Kales et al., 2015).

Mid-stage progressive and decline support features. Often the most commonly used approaches for people with intellectual disability are the same as those used in the general population, but may need adaptation. These include developing an understanding of dementia (Buijssen, 2005); anxiety and stress reduction (Dodd, 2010); life story work (Gibson, 1994); reminiscence, (Pinquart \& Forstmeier, 2012), reality orientation and validation techniques (Kerr, 2007); and helping peers to understand dementia (Dodd et al., 2005a-c). These techniques can have a fruitful effect on cognitive capacity, depression, and quality of life (Pinquart \& Forstmeier, 2012). A range of other therapeutic approaches also may be effective with people with intellectual disability and dementia, including music therapy (Ueda, Suzukamo, Sato, \& Izum, 2013), aromatherapy, sensory stimulation (including Snoezelen), touch, and the use of electronic devices, domotica (smart homes), and entertainment. There is further information regarding specific activities and interventions for different stages of dementia from Kalsy-Lillico (2014). 
The interventions will be consistent with those used generally by intellectual disability professionals, where the emphasis is on a person-centered approach with interdisciplinary and multiagency working. These will include the provision of accurate and timely information; formulation; interventions to maximise and maintain independence, skills and health; and at the same time promoting safety comfort, and dignity. Reducing excessive demands and simplifying routines are is important, while minimising avoidable changes, especially any exclusion from appropriate health and social care services. The assumption is that when an adult is in an unsuitable environment for his or her needs (e.g., the physical environment places the person at risk, the person is isolated or bullied) and may be depressed, a change of environments may be beneficial (Gaertner, 2016). Furthermore, awareness needs to be maintained regarding the person's changing needs and interventions need to be reviewed at regular intervals.

\section{Focus on programmatic processes}

Provision of supportive environments can be engineered so that people with dementia can remain in the family home, if the home is suitable as a care setting and this is wanted by the person with intellectual disability. Supports in such situations would entail providers working closely with family carers to sustain their efforts at providing supervision and basic personal supports, as well as dementia-proofing their home (when that is needed) and teaching techniques to address behaviour. Also, when home-based caregiving is not viable or the person's care needs have exceeded the capacity of family carers, then alternatives for housing should be made available and anticipated to allow a planned process. Such alternatives may include small group living homes, preferably those that are dementiacapable and have sufficient staffing to provide extended care as dementia progresses including night-time care. These alternatives may also need additional support to provide dementia suitable physical and social environments (BPS, 2015). Examples of such community based dementia group homes are becoming more prevalent and proving to be suitable alternative care environments (Janicki, 2015; National Institute on Aging, 2013; Van Zadelhoff, Verbeek, Widdershoven, van Rossum, \& Abma T. 2011; Wilson, Malmberg, \& 
Zarit,_1993). Quality of care in such settings has been discussed by Watchman (2012), Janicki, Dalton, McCallion, \& Zendell, (2005) and Janicki (2011). Janicki noted that the elements of homes demonstrating quality include clinically relevant early and periodic assessment; functional modifications in the living setting; staff education for stage-adapted care; and flexible long-term services provision that recognises and plans for progression of decline and loss of function.

Environmental adaptations are also now seen as important interventions for effective dementia care (Canadian Psychological Association, 2014; De Vreese et al., 2012; Kerr, 2007), as one of the initial line of intervention before treatment using medication for behavioural problems. Dementia enabled designs, explored further in Gaertner (2016), Jokinen et al., (2013), and McCarron, McCallion, Reilly, \& Mulryan, (2014), may result in fewer falls, decrease in stress, confusion, and anxiety and could lead to a reduction in the use of anti-psychotics and need for sedation. They also can increase quality of care, as staff are usually trained to understand and provide supports for people with dementia, and the environments generally are adapted to enable residents to be as autonomous as they can be.

Focus on individualized interventions

As dementia progresses, people become less able to instigate meaningful activities. This does not necessarily mean that they do not want to engage in activities, only that at times they can no longer initiate them themselves. There is evidence from clinical practice that giving people meaningful, but failure-free, activities can reduce stress and adverse behaviours and encourage a sense of well-being, accomplishment and improved mood. Failure-free activities need to be appropriate to the individual (Sheridan, 1997), and should include a range of involvements that engage the adults in easy tasks where success is optimized, such as looking at magazines, carers sitting with the person describing what is 
happening outside, talking about a favourite object, or going for a walk (BPS, 2015; KalsyLillico, 2014).

BPSD: Consideration also needs to be given to behavioural and psychological symptoms of dementia (BPSD) which is a description used typically more with people with dementia within the general population than in services for people within intellectual disability services. BPSD may include agitation, aberrant motor behaviour, anxiety, elation, irritability, depression, apathy, disinhibition, delusions, hallucinations, and sleep or appetite changes, which are present at one time or another in the majority of adults affected by dementia (Devshi et al., 2015; Kales et al., 2015; Purandare, Allen, \& Burns, 2000). BPSD may be more commonly associated with dementia in individuals with Down syndrome, and is often observed even before the clinical dementia diagnosis is made (Dekker et al., 2015). Accurate recognition of BPSD may increase awareness and understanding of behavioural and psychological issues, thus enabling adaptive caregiving and provision of appropriate interventions.

\begin{abstract}
Although closely associated with an advancing dementia, BPSD may be caused by factors other than the dementia. In particular, people with dementia may have a range of comorbid conditions that are overlooked through diagnostic overshadowing (BPS, 2015). Carers and support staff may fail to recognise that the person with dementia is experiencing pain and offer timely treatment, with symptoms presenting as BPSD (BPS, 2015). People with intellectual disabilities and dementia may experience sleep disturbance, hyperactivity (including agitation and aggression), affective symptoms (such as anxiety and depression), and delusions and hallucinations. Given that various stimuli may set-off an incident of such changed behaviour, it is important to continue to assess all physical and psychological causes. It has been suggested that a combination of non-pharmacological and careful use of pharmacological interventions can help in the therapeutic managing of BPSD (Cerejeira,
\end{abstract}


Lagarto, \& Mukaetova-Ladinska, 2012), German Association for Psychiatry, Psychotherapy and Psychosomatics (DGPPN), 2016)).

Behaviour Management: Behaviour management therapies, and carer and residential staff education appear to have lasting effectiveness in the management of BPSD (Livingston et al., 2005), while sensory interventions, and music therapy may have short-term effects. Behavioural approaches in the general population recognise the importance of that people may not be having their needs met and the need to manage underlying causes, including discomfort, loneliness, and anxiety (Cohen-Mansfield, Dakheel-Ali, Marx, Thein, \& Regier 2015). Positive behaviour support approaches have become established as a preferred approach in the UK when working with people with intellectual disability who present behaviours that can be perceived as challenging (BPS, 2015; Department of Health, 2014; Gore et al.,2013; Royal College of Psychiatrists, 2007), and have been proposed for use with persons with dementia. Positive behaviour support emphasizes person-centred values, aims to enhance community presence, increases personal skills and competence, and ensures dignity and respect is maintained for the person being supported (Dodd, Turk, \& Christmas, 2009). Although there is very limited research evidence supporting its use in older people with intellectual disability and dementia (Fonseca et al., 2015), it is increasingly being used in clinical practice. In general, when a diagnosis of dementia is suspected a shift in value from increasing skills to maintaining skills and accepting decreasing skills can be helpful in terms of reducing stress of the individual. Such applications of behaviour-analytic approaches examine the environmental factors that may influence the frequency and intensity of dementia symptoms and the identification of contingencies that aid in individualized care planning and that decrease excess behaviours in older adults with dementia (Trahan, Kahng, Fisher, \& Hausman, 2011). It is not known how these techniques affect the generalization or maintenance of behaviour change, which is particularly important given that individuals with dementia demonstrate deterioration in skills over time. 
In all cases where there is behaviour that challenges other people, the standards of assessment of the behaviour and subsequent intervention should occur as outlined in guidance, such as "Challenging behaviour: a unified approach" (Royal College of Psychiatrists, 2007) and its update (Royal College of Psychiatrists, 2016). This includes ensuring that any intervention addresses the person, the environment, and the interaction between the two.

Environment: Finally, environmental adaptations are now considered an important intervention for dementia (Canadian Psychological Association, 2014; De Vreese et al., 2012; Kerr, 2007), as one of the initial line of interventions before treatment using medication for behavioural problems. Dementia enabled design, explored further in Gaertner (2016) and Jokinen et al., (2013), may result in decreases in falls, and decreases in stress, confusion and anxiety and can lead to a reduction in the use of anti-psychotics and need for sedation.

\begin{abstract}
By understanding dementia, adopting a clear philosophy of care which includes a flexible and person-centred approach, tailoring interventions to the needs of the person and the stage of dementia, and using the whole range of psychological and non-pharmacological interventions, the quality of life for the person with intellectual disability and dementia, their peers, staff and carers can be maintained so that the person leads a fulfilling life.
\end{abstract}

Later stage supports. Eventually decline will compromise cognitive and physical function, and be associated with bodily system failures, leading to a progression of gross dysfunction and death. During this stage, often PDS take on different features, with interventions focusing on maintenance of bodily functions, maintaining comfort, and the provision of palliative care (see McCallion et al., 2017; Service et al., 2017). In particular, issues related to dysphagia become paramount, with difficult decisions needing to be made on whether the person should be 'eating at risk' when the person presents with unavoidable risk of aspiration (DGPPN, 2016, p.96-97). It is recognized that end-of-life care and related support 
considerations come into play among these individuals when most are in the advanced stage of dementia (McCallion et al., 2017). End stage PDS generally encompasses determining whether advanced dementia is present, proposing use of palliative care services (including hospice), integrating efforts between intellectual disability and palliative care providers, and offering specialized aid to family carers, and training for paid carers on end-of-life care and supports.

\section{Pharmacological interventions}

The two major classes of medications to reduce the cognitive symptoms of dementia are acetylcholinesterase inhibitors (Als), such as donepezil, which increase central acetylcholine concentration, and an N-methyl-D-aspartate (NMDA) antagonist (such as memantine). Neither are believed to have disease-modifying properties and are therefore not used to prevent the long-term histopathological progression of disease. However, in the short to medium term, they have been shown to slow clinical deterioration, and there is a strong evidence-base for their use in the general population. Furthermore, recent evidence suggests that continuation of acetylcholine esterase inhibitors particularly donepezil, even in those with more severe dementia, resulted in better cognitive outcomes compared to stopping the medication (Howard et al., 2012) and delayed admission to nursing homes (Howard et al., 2015). These drugs are therefore recommended for treatment of dementia, particularly Alzheimer's disease, through guidance from the US (National Institute on Aging, 2016; Moran, Rafii, Keller, Singh, \& Janicki, 2013) and in the UK (NICE, 2012). These guidelines explicitly include individuals with intellectual disability and Down syndrome in their recommendations. The NICE guidance states that 'the difficulty in staging dementia by using the MMSE, in people with intellectual disabilities should not disadvantage them, thus introducing some flexibility for prescribers.'

Most research into Alzheimer's disease in people with intellectual disability has been with individuals with Down's syndrome due to their neuropathological association with the risk of developing an Alzheimer-like dementia (Wiseman et al., 2015). Acetylcholine esterase 
inhibitors are the most commonly prescribed anti-dementia medications in this population. A review of the literature found a few small controlled studies confirm that donepezil and rivastigmine are well tolerated in the people with Down's syndrome (Eady, Courtenay, \& Strydom, 2015; Prasher, 2004). These studies have some methodological flaws, including small sample size, choice of controls, and length of follow-up. Other than commenting on safety and the side effect profile, it is therefore not possible to draw firm conclusions on the efficacy of acetylcholine esterase inhibitors on cognition or functioning, or the control of associated behavioural and psychiatric symptoms in people with Down syndrome and dementia (Strydom et al., 2009). There is however some evidence that these treatments may reverse or delay the symptoms of dementia during the early and middle stages of dementia (Lott, Osann, Doran, \& Nelson, 2002). Further evidence is required, including from non-randomized designs, as it may not be possible to complete further randomized control studies (Glover, Bernard, Branford, Holland, \& Strydom, 2014). In contrast, a recent prospective double-blind, randomized control trial compared memantine with placebo in people with Down syndrome and concluded that memantine is not effective for the treatment of dementia in this population (Hanney et al., 2012). A major trial of vitamin $E$ for dementia in Down syndrome has also demonstrated a lack of efficacy (Sano et al., 2016).

\author{
A 2015 Cochrane review of medication for dementia in people with Down syndrome \\ (Livingstone, Hanratty, McShane, \& Macdonald, 2015) concluded that overall, the quality of \\ evidence is low which prevents firm conclusions to be made and the authors argued for \\ further trials. However, it is probably unlikely to conduct trials based on withholding \\ treatments (in a placebo arm) from individuals with dementia if those treatments are \\ accepted practice and recommended by current guidance. Although evidence for the use of \\ medication is lacking, current clinical consensus is that it should not be stopped if it \\ beneficial for an individual with intellectual disability and dementia.
}

Pharmacological management of behavioural issues in people with intellectual disability are discussed in BPS (2015), Eady et al., (2015), and Sheehan et al., (2015). In summary, the use of psychotropic drugs (especially antipsychotics) or sedatives for people with intellectual 
disability and behavioural problems remain controversial, particularly in older adults with dementia, and current guidelines (BPS, 2015; American Psychiatric Association, 2016) are to use alternative treatments such as psychological, therapeutic and behavioural interventions as first-line options, but in specific situations medication can be considered (e.g., presence of specific distressing symptoms such as hallucinations and serious sleep problems). If psychotropic drugs are used, they should be carefully monitored and used for short periods. A general principle is that medication treatment for psychiatric disorders in older people with intellectual disability should be started at low dosages and be increased cautiously while monitoring response and side-effects (Eady et al., 2015). Older adults with intellectual disability are at risk of polypharmacy (American Psychiatric Association, 2016), and older age may be a risk factor for development of side effects.

\section{Commentary}

The Summit together with Shakespeare, Zeilig \& Mittler (2017) believe that this Consensus Statement is consistent with the Convention on the rights of persons with disabilities, and that the convention does include consideration of dementia. The Convention on the Rights of Persons with disabilities was adopted in 2008, and represented a paradigm shift from a medical model of disability to a social model for people recognized as having a disability. However, there is little evidence that persons with dementia are being included in its implementation at national level. The Summit (Watchman et al., 2017) recommended that a human rights approach be adopted that ensures that: everyone with dementia including people with intellectual disability, are provided with information in an accessible format to make people aware of their rights; intellectual disability organizations respond to a call for greater advocacy on behalf of their members with an intellectual disability and dementia and liaise with dementia organizations to share an advocacy role for families; that all nations review laws and policies to replace regimes of substitute decision-making by supported decision-making, which respects the person's autonomy, will and preferences; deinstitutionalization should be achieved and legal capacity must be restored to all persons with intellectual disabilities, who must be able to choose where and with whom to live.

\footnotetext{
URL: http:/mc.manusçiptcentral.com/camh
} 
The Summit believes that what follows the diagnosis of dementia among adults with intellectual disability forms a phase of life that requires special attention from providers, clinicians, and carers. It is noted that in many countries most people with intellectual disability who develop dementia are usually known to services; thus, the Summit believes that PDS should be aimed at adapting what is already known about and in place for the person and in accessing additional supports to meet their changing needs. The Summit also recognised that while some countries already have in place policies, strategies, and formal support systems to support people with intellectual disabilities and dementia, in other countries it is acknowledged that such supports may be absent or only rudimentary and thus believes that support need to be developed and delivered by a range of nongovernmental, family and self-help organisations. The key is that some degree of support needs to be available to aid the person with an intellectual disability with dementia and their immediate carers and /or support staff.

The Summit also believes that on a structural level, the effectiveness of PDS applications to adults with intellectual disability need to be fully evaluated in more complex environments to ensure that interventions and care practices undertaken have a positive effect on the person's quality of life. The support may be through specific non-pharmacological and / or pharmacological approaches and stage-adapted changes in care practices. Further, as what constitutes an appropriate intervention will change as dementia advances, so it will need to be individualised to the stage-associated ability and to the changing needs of the person. In addition, the timeline for PDS needs to be acknowledged as the period from the moment of diagnosis of dementia through to the end of the person's life. The model we have laid out should serve as a starting point for effective designs and efforts.

Overall, the Summit recognises that there is limited research evidence for interventions (whether pharmacological or non-pharmacological) for people with intellectual disability and dementia; however, there are a range of resources and guidelines that describe these 
approaches drawn from clinical practice. Ongoing post diagnostic support is essential, and the model components, as in place for the general population, and proposed for use within the intellectual disability field, need to be individualised and adapted to each person's needs as the neuropathology and resultant dementia progresses. Given this, the Summit's position is consistent with other organizations as recognizing PDS as a necessary ingredient in care among those individuals with intellectual disability affected by dementia.

Lastly, the Summit recognises the importance of addressing the process of PDS and believes that this Consensus Statement might be useful to clinicians, providers, and national organizations, in both planning for people with intellectual disability as they age and develop neuropathologies and in adapting services to include more focus on geriatric and gerontological issues in general, and dementia related care in particular.

Recommendations for future research:

The Summit recommends that research into the areas outlined below is commissioned and undertaken

1. The prevalence and nature of BPSDs in adults with intellectual disability who develop dementia, and whether there is a difference in prevalence and nature related to the cause of the person's intellectual disability or by the type of dementia.

2. The effectiveness of non-pharmacological interventions both individually and in combination for symptoms of dementia and for quality of life for people with intellectual disability and dementia.

3. The interaction between the use of medications and non-pharmacological interventions in reducing BPSD and improving quality of life.

4. The effect on carers and support staff of different models of support looking at issues such as resilience, emotional labour, and staff turnover.

\section{References}


Abley, C., Manthorpe, J. B., Keady, J., Samsi, K., Campbell, S., Watts, S., and Robinson, L. 2013. Patients' and carers' views on communication and information provision when undergoing assessments in memory services. Journal of Health Services Research \& Policy 18(3): 167-173.

Alzheimer Scotland. 2011. Pillars model of post diagnostic support. Edinburgh, Scotland: Author. Accessed from: http://www.alzscot.org/campaigning/five_pillars

American Geriatrics Society. 2013. Five things physicians and patients should question. In: Choosing wisely. Philadelphia, PA: ABIM Foundation.

American Psychiatric Association. 2013. Five things physicians and patients should question. In: Choosing wisely. Philadelphia, PA: ABIM Foundation.

American Psychiatric Association. 2016. The American Psychiatric Association Practice guideline on the use of Antipsychotics to Treat Agitation or Psychosis in Patients with Dementia. Arlington, VA: Author.

Backhouse, A., Dickens, C., Richards, D., \& McCabe, R. 2015. Key components in models of community-based interventions coordinating care in dementia: a mixed studies systematic review protocol. Systematic Reviews 4: 156.

https://www.ncbi.nlm.nih.gov/pmc/articles/PMC4636819/

British Psychological Society / Royal College of Psychiatrists. 2015. Dementia and people with intellectual disabilities. Guidance on the assessment, diagnosis, interventions and support of people with intellectual disabilities who develop dementia. Leicester, UK: British Psychological Society.

British Psychological Society Dementia Advisory Group. 2016. Psychological dimensions of dementia: Putting the person at the centre of care. Leicester, UK. British Psychological Society.

Buijssen, H. 2005. The simplicity of dementia. London, UK: Jessica Kingsley Publishers

Canadian Psychological Association. 2014 "Psychology works" fact sheet: environmental adaptations to dementia. Ottawa, Canada: Author. Accessed from:

http://www.cpa.ca/docs/File/Publications/FactSheets/PsychologyWorksFactSheet_Environ mentalAdaptationsToDementia.pdf

Carvalho, C. L., Ardore, M., \& Castro, L. R. de. 2015. Family caregivers and the aging of the person with intellectual disabilities: Implications to care. Revista Kairós Gerontologia 18(3): 333-352.

Cerejeira, J., Lagarto, L., \& Mukaetova-Ladinska, E. B. 2012. Behavioral and psychological symptoms of dementia. Frontiers in Neurology, 3: 73. Published online 2012 May 7. Prepublished online 2012 Feb 24. doi: 10.3389/fneur.2012.00073.

Cohen-Mansfield, J., Dakheel-Ali, M., Marx, M. S., Thein, K., \& Regier, N.G. 2015. Which unmet needs contribute to behavior problems in persons with advanced dementia? Psychiatry Research 228(1): 59-64. 
Courtenay, K., Jokinen, N., \& Strydom, A. 2010. Caregiving and adult with intellectual disabilities affected by dementia. Journal of Policy and Practice in Intellectual Disabilities 7(1): 26-33.

Dawson, A., Bowes, A., Kelly, F., Velzke, K., \& Ward R. 2015. Evidence of what works to support and sustain care at home for people with dementia: a literature review with a systematic approach. BMC Geriatrics 15: 59-76.

Dekker, A. D., Strydom, A., Coppus, A.M., Nizetic, D., Vermeiren, Y., Naudé, P. J., Van Dam, D., Potier, M. C., Fortea, J., \& De Deyn, P. P. 2015. Behavioural and psychological symptoms of dementia in Down syndrome: Early indicators of clinical Alzheimer's disease? Cortex 73: 36-61. doi: 10.1016/j.cortex.2015.07.032. Epub 2015 Aug 13.

Demenz-Service NRW. 2016. Menschen mit Demenz und geistiger Behinderung begleiteneine Handreichung für Mitarbeitende der Behinderten- und Altenhilfe [Supporting people with dementia and intellectual disability.A guidline for staff working in the field of intellectual disabilities and care for the elderly]. Ministerium für Gesundheit, Emanzipation, Pflege und Alter des Landes Nordrhein-Westfalen.

Dening KH, King M, Jones L, Vickestaff V, \& Sampson EL. 2016. Advance care planning in dementia: Do family carers know the treatment preferences of people with early dementia? PLOS ONE 11(7): e0159056. doi:10.1371/journal.pone.0159056

Department of Health. 2014. Positive and proactive care: reducing the need for restrictive interventions. London, UK: Author.

Department of Health 2016. Dementia: post-diagnostic care and support. Accessed at https://www.gov.uk/government/publications/dementia-post-diagnostic-care-and-support.

De Vreese, L. P., Mantesso, U., De Bastiani, E., Weger, E., Marangani, A. C., \& Gomiero, T. 2012. Impact of dementia-derived nonpharmacological intervention procedures on cognition and behavior in older adults with intellectual disabilities: A 3-year follow-up study. Journal of Policy and Practice in Intellectual Disabilities 9(2): 92-102.

Devshi, R., Shaw, S., Elliott-King, J., Hogervorst, E., Hiremath, A., Velayudhan, L., Kumar, S., Baillon, S., \& Bandelow, S. 2015. Prevalence of behavioural and psychological symptoms of dementia in individuals with learning disabilities. Diagnostics (Basel, 5(4): 564-576. doi: 10.3390/diagnostics5040564

DGPPN. 2016. S3 Guidelines “Dementia”. The German Association for Psychiatry, Psychotherapy and Psychosomatics (DGPPN). Accessed from: https://www.dgppn.de/fileadmin/user_upload/_medien/download/pdf/kurzversionleitlinien/S3-LL-Demenzen-240116-1.pdf

Dodd, K. 2010. Psychological and other non-pharmacological interventions in services for people with learning disabilities and dementia. Advances in Mental Health and Learning Disabilities 4: 28-36.

Dodd, K., Bush, A., \& Livesey, A. 2015. Developing and piloting the QOMID - Quality outcome measure for individuals with intellectual disabilities and dementia. Advances in Mental Health and Intellectual Disabilities 9(6): 298-311. 
Dodd, K., Turk V., \& Christmas, M. 2005a. The journey of life: How people change from babies to older people. Birmingham, UK: BILD Publications.

Dodd, K., Turk V., \& Christmas, M. 2005b. About my friend: For friends of people with Down's syndrome and dementia. Birmingham, UK: BILD Publications.

Dodd, K., Turk V., \& Christmas, M. 2005. About Dementia-for people with learning disabilities. Birmingham, UK: BILD Publications.

Dodd, K., Turk, V., \& Christmas, M. 2009. Resource pack for carers of adults with Down's syndrome and dementia ( $2^{\text {nd }} E d$.). Birmingham, UK: BILD Publications.

Eady, N., Courtenay, K., \& Strydom, A. 2015. Pharmacological management of behavioral and psychiatric symptoms in older adults with intellectual disability. Drugs \& Aging 32(2): 95-102.

Fonseca, L. M., de Oliveira, M. C., de Figueiredo Ferreira Guilhoto, L. M., Cavalheiro, E. A., Bottino, C. M. 2014. Bereavement and behavioral changes as risk factors for cognitive decline in adults with Down syndrome. Neuropsychiatric Disease and Treatment 10: 22092219. doi: 10.2147/NDT.S68831.

Gaertner, C. 2016. Ageing in Place und ressourcenorientierte Begleitung bei Menschen mit geistiger Behinderung [Aging in place and resource-oriented support for people with intellectual disabilities]. In S. V. Müller \& C. Gaertner (Hrsg.). Lebensqualitaet im Alter Perspektiven für Menschen mit geistiger Behinderung und psychischen Erkrankungen [Quality of life in old age - perspectives for people with intellectual disabilities and mental illnesses] (pp. 219-236). Wiesbaden, Germany: Springer Fachmedien S.

Gibson, F. 1994. Reminiscence and recall: A guide to good practice. London, UK: Age Concern England.

Gitlin, L. N., Kales, H. C., \& Lyketsos, C.G. 2012. Nonpharmacologic management of behavioral symptoms in dementia. JAMA 308(19): 2020-2029.

Glover, G., Bernard, S., Branford, D., Holland, A., \& Strydom, A. 2014. The use of medication for challenging behaviour in people with intellectual disability. British Journal of Psychiatry 205(1): 6-7; DOI: 10.1192/bjp.bp.113.141267

Gore, N. J., McGill, P., Toogood, S., Allen, D., Hughes, J. C., Baker, P., Hastings, R., Noone, S. J., \& Denne, L. D. 2013. Definition and scope for positive behavioural support. International Journal of Positive Behavioural Support 3(2): 14-23.

Hanney, M., Prasher, V., Williams, N., Jones, E. L., Aarsland, D., Corbett, A., \& Ballard, C. 2012. Memantine for dementia in adults older than 40 years with Down's syndrome (MEADOWS): a randomised, double-blind, placebo-controlled trial. The Lancet 379(9815):528-536.

Health Quality Ontario. 2008. Caregiver- and patient-directed interventions for dementia: an evidence-based analysis. Ontario Health Technology Assessment Series 8(4): 1-98. 
Howard, R., McShane, R., Lindesay, J., Ritchie, C., Baldwin, A., Barber, R., Burns, A., Dening, T., Findlay, D., Holmes, C., Hughes, A., Jacoby, R., Jones, R., Jones, R., McKeith, I., Macharouthu, A., O'Brien, J., Passmore, P., Sheehan, B., Juszczak, E., Katona, C., Hills, R., Knapp, M., Ballard, C., Brown, R., Banerjee, S., Onions, C., Griffin, M., Adams, J., Gray, R., Johnson, T., Bentham, P., \& Phillips, P. 2012. Donepezil and Memantine for moderate-tosevere Alzheimer's disease. New England Journal of Medicine 366: 893-903.

Howard, R., McShane, R., Lindesay, J., Ritchie, C., Baldwin, A., Barber, R., Burns, A., Dening, T., Findlay, D., Holmes, C., Jones, R., Jones, R., McKeith, I., Macharouthu, A., O'Brien, J., Sheehan, B., Juszczak, E., Katona, C., Hills, R., Knapp, M., Ballard, C., Brown, R., Banerjee, S., Adams, J., Gray, R., Johnson, T., Bentham, P., \& Phillips, P.2015. Nursing home placement in the Donepezil and Memantine in moderate to severe Alzheimer's disease (DOMINO-AD) trial: secondary and post-hoc analyses. The Lancet Neurology 14(12): 1171-1181.

International Psychogeriatric Association. 2015. IPA complete guides to behavioral and psychological symptoms of dementia: Specialists guide. Milwaukee, WI: Author. Accessed from https://www.ipa-online.org/publications/guides-to-bpsd

Janicki, M. P. 2011. Quality outcomes in group home dementia care for adults with intellectual disabilities. Journal of Intellectual Disability Research 55(8): 763-776.

Janicki, M. P. 2015. Specialization evolution of group homes for dementia-related care of adults with intellectual disabilities. Alzheimer's \& Dementia 11(1): 236-P237.

Janicki, M. P., Dalton, A. J., McCallion, P., Zendell, A. 2005. Group home care for adults with intellectual disabilities and Alzheimer's disease. Dementia 4(3): 361-385.

Jokinen, J., Janicki, M. P., Keller, S. M., McCallion, P., Force, L. T. and the National Task Group on Intellectual Disabilities and Dementia Practices. 2013. Guidelines for structuring community care and supports for people with intellectual disabilities affected by dementia. Journal of Policy and Practice in Intellectual Disabilities 10(1): 1-28.

Kales, H. C., Gitlin, L. N., \& Lyketsos, C. G. 2015. Assessment and management of behavioral and psychological symptoms of dementia. BMJ 350: h369.

Kalsy-Lillico, S. 2014. Living life with dementia: Enhancing psychological wellbeing. In: Watchman, K. (ed), Intellectual disability and dementia: Research into practice. London, UK: Jessica Kingsley Publishers.

Kerr, D. 2007. Understanding learning disability and dementia: Developing effective interventions. London, UK: Jessica Kingsley Publishers.

Kerr, D., \& Innes, M. 2000. What is dementia? A booklet for adults with a learning disability. Edinburgh, Scotland: Scottish Down's Syndrome Association.

Livingston, G., Johnston, K., Katona, C., Paton, J., Lyketsos, C.G., and Old Age Task Force of the World Federation of Biological Psychiatry. 2005. Systematic review of Psychological Approaches to the Management of neuropsychiatric symptoms of dementia. American Journal of Psychiatry 162(11): 1996-2021. 
Livingstone, N., Hanratty, J., McShane, R., \& Macdonald, G. 2015. Pharmacological Interventions for cognitive decline in people with Down syndrome (review). Cochrane Library. Published Online: 29 OCT 2015. Accessed at http://onlinelibrary.wiley.com/doi/10.1002/14651858.CD011546.pub2/pdf

Lott, I. T., Osann, K., Doran, E., \& Nelson, L. 2002. Down syndrome and Alzheimer disease: response to donepezil. Archives of Neurology 59(7): 1133-1136.

Maaskant, M., \& Schuurman, M. 2012. Dementie bij mensen met een verstandelijke handicap: brochure voor verwanten en professionele ondersteuners [Dementia in people with intellectual disabilities: brochure for relatives and professional support staff]. Utrecht, the Netherlands: Kennisplein Gehandicaptensector. Accessed from: http://www.dementiezorg.nl/wp-content/uploads/2015/11/Brochure_dementie.pdf

McCallion, P., Hogan, M., Santos, F. H., McCarron, M., Service, K., Stemp, S., Keller, S., Fortea, J., Bishop, K., Watchman, K., Janicki, M. P. and the Working Group of the International Summit on Intellectual Disability and Dementia. 2017. Consensus Statement of the International Summit on Intellectual Disability and Dementia Related to End-of-life Care in Advanced Dementia. Journal of Applied Research in Intellectual Disability. [early view]. DOI: 10.1111/jar.12349

McCarron M, McCallion P, Reilly E, Mulryan N. 2014 Responding to the challenges of service development to address dementia needs for people with an intellectual disability and their caregivers. In: K. Watchman (Ed.), Intellectual Disability and Dementia: Research into Practise (pp. 241 -269). London, UK: Jessica Kingsley Publishers.

Moran, J. A., Rafii, M. S., Keller, S. M., Singh, B. K., \& Janicki, M. P. 2013. The National Task Group on Intellectual Disabilities and Dementia Practices consensus recommendations for the evaluation and management of dementia in adults with intellectual disabilities. Mayo Clinic Proceedings 88(8): 831-840.

National Institute for Health and Clinical Excellence (NICE). 2012. Dementia: Supporting people with dementia and their carers in health and social care. Clinical guideline CG42. Accessed at http://www.nice.org.uk/guidance/CG42

National Institute on Aging. 2013. Caring for a person with Alzheimer's disease: Your easyto-use guide from the National Institute on Aging. Bethesda, Maryland: Author.

National Institute on Aging. 2016. Alzheimer's Disease Medication. NIH Publication No. 16AG-3431. Bethesda, Maryland: Author.

Nederlandse Vereniging voor Klinische Geriatrie. 2014. Richtlijn Diagnostiek en Behandeling van dementia. Utrecht, the Netherlands: Nederlandse Vereniging voor Klinische Geriatrie. Accessed from: www.nvvp.net/stream/richtlijn-diagnostiek-en-behandeling-van-dementie2014

Olazaran, J., Reisberg, B., Clare, L., Cruz, I., Pena-Casanova, J., del Ser, T., Woods, B., Beck, C., Auer, S., Lai, C., Spector, A., Fazio, S., Bond, J., Kivipelto, M., Brodaty, H., Rojo, J. M., Collings, H., Teri, L., Mittelman, M., Orrell, M., Feldman, H. H., \& Muñi, R. 2010. 
Nonpharmacological therapies in Alzheimer's disease: a systematic review of efficacy. Dementia and Geriatric Cognitive Disorders 30(2): 161-78.

Pinquart, M., \& Forstmeier, S. 2012. Effects of reminiscence interventions on psychosocial outcomes: a meta-analysis. Aging and Mental Health 16: 541-558.

Prasher, V. P. 2004. Review of donepezil, rivastigmine, galantamine and memantine for the treatment of dementia in Alzheimer's disease in adults with Down syndrome: implications for the intellectual disability population. International Journal of Geriatric Psychiatry 19(6): 509-515.

Prince, M., Comas-Herrera, A., Knapp, M., Guerchet, M., Karagiannidou, M. 2016. World Alzheimer Report 2016: Improving healthcare for people living with dementia coverage, Quality and costs now and in the future. London, UK: Alzheimer's Disease International.

Purandare N, Allen NHP, Burns A. 2000. Behavioural and psychological symptoms of dementia. Reviews in Clinical Gerontology 10(3): 245-260.

Royal College of Psychiatrists. 2007. Joint Guidelines of the Royal College of Psychiatrists, the British Psychological Society and the Royal College of Speech and Language Therapists. Challenging behaviour: a unified approach - update Clinical and service guidelines for supporting children, young people and adults with intellectual disabilities who are at risk of receiving abusive or restrictive practice. London, UK: Royal College of Psychiatrists.

Royal College of Psychiatrists. 2016. Challenging behaviour: a unified approach - update: Clinical and service guidelines for supporting children, young people and adults with intellectual disabilities who are at risk of receiving abusive or restrictive practices. .. London, UK: Royal College of Psychiatrists. Accessed from: https://www.rcpsych.ac.uk/pdf/FR_ID_08.pdf

Sano, M., Aisen, P. S., Andrews, H. F., Tsai, W. Y., Lai, F., Dalton, A. J. \& International Down Syndrome and Alzheimer's Disease Consortium. (2016). Vitamin E in aging persons with Down syndrome: A randomized, placebo-controlled clinical trial. Neurology 86(22): 20712076. doi: 10.1212/WNL.0000000000002714. Epub 2016 May 4.

Shakespeare, T., Zeilig, H., \& Mittler, P. 2017. Rights in mind. Thinking differently about dementia and disability. Dementia (London). Jan 1:1471301217701506. doi:

$10.1177 / 1471301217701506$

Sheehan, R., Hassiotis, A., Walters, K., Osborn, D., Strydom, A., \& Horsfall, L., 2015. Mental illness, challenging behaviour, and psychotropic drug prescribing in people with intellectual disability: UK population based cohort study. BMJ, 351, h4326

Service, K., Watchman, K., Hogan, M., Cadovius, N., Janicki, M. P., \& Berankova, A. 2017. Dying well with an intellectual disability and dementia? Journal of Dementia Care. July/August 2017 Vol 25 No 4, 22-25.

Sheridan, C. 1997. Failure-free activities for the Alzheimer's patient: A guidebook for caregivers. Forest Knolls, CA: Elder Books. 
Strydom, A., Lee, L. A., Jokinen, N., Shooshtari, S., Raykar, V., Torr, J., Tsiouris, J. A., Courtenay, K., Bass, N., Sinnema, M., \& Maaskant, M. A. 2009. Report on the State of Science on Dementia in People with Intellectual Disabilities. IASSID Special Interest Research Group on Ageing and Intellectual Disabilities. Accessed from: http://www.opadd.on.ca/News/documents/dementialASSID.report.pdf

Szymczynska, P., Innes, A., Forrest, L., \& Stark, C. 2010. Diagnostic and post-diagnostic service provision to people with dementia and their carers with particular interest in remote and rural populations. Inverness, Scotland: NHS Highland.

Tiziano, G., Hogan, M., Jokinen, N., Larsen, L., Beránková, A., Santos, F. H., Watchman, K., Janicki, M. P., \& Crow, J. 2017. Challenges and perspectives in the caregiving of ageing people with intellectual disability affected by dementia: Commentary from the International Summit on Intellectual Disability and Dementia. Report in preparation.

Trahan, M. A., Kahng, S-W., Fisher, A. B., \& Hausman, N. L. 2011. Behavior-analytic research on dementia in older adults. Journal of Applied Behavior Analysis 44(3): 687-691.

Tuffrey-Wijne, I, \& Watchman, K. 2014. Sharing the diagnosis of dementia: Breaking bad news to people with an intellectual disability. In K. Watchman (Ed.), Intellectual disability and dementia: research into practise (pp. 184 - 203). London, UK: Jessica Kingsley Publishers.

Ueda, T., Suzukamo, Y., Sato, M., \& Izum, S-I. 2013. Effects of music therapy on behavioral and psychological symptoms of dementia: a systematic review and meta-analysis. Ageing Research Reviews 12(2): 628-641.

Van Zadelhoff, E., Verbeek, H., Widdershoven, G., van Rossum, E., \& Abma, T. 2011. Good care in group home living for people with dementia. Experiences of residents, family and nursing staff. Journal of Clinical Nursing 20(17/18): 2490-2500.

Watchman, K. 2012. People with a learning disability and dementia: reducing marginalization. Journal of Dementia Care 20(5): 35-39.

Watchman, K., Janicki, M.P., Hogan, M., Udell, L., Quinn, S., \& Beránková, A. 2017. Consensus Statement of the International Summit on Intellectual Disability and Dementia on Valuing the Perspectives of Persons with Intellectual Disability. In submission with the Journal of Learning Disability.

Watchman, K., Tuffrey-Wijne, I., \& Quinn, S. 2015. Jenny's diary. Paisley, Scotland: University of West of Scotland. Accessed from: http://www.uws.ac.uk/jennysdiary/

Watts, S., Cheston, R., and Moniz-Cook E. 2013. Post-diagnostic support for people living with dementia: An interim report prepared for the Faculty of Psychologists working with Older People and the Dementia Action Alliance. Accessed from: http://www.dementiaaction.org.uk/assets/0000/3825/Faculty_of_Psychologists.pdf

Wilson, N. L., Malmberg, B., Zarit, S. H. 1993. Group homes for people with dementia: Swedish example. Gerontologist 33(5): 682-686. 
Wiseman, F. K., Al-Janab, T., Hardy, J., Karmiloff-Smith, A., Nizetic, D., Tybulewicz, V. L. J., Fisher, E. M. C., \& Strydom, A. (2015). A genetic cause of Alzheimer's disease: mechanistic insights from Down syndrome. Nature Reviews Neuroscience 16(9): 564-574.

World Health Organization (WHO). 2012. Dementia: A public health priority. Geneva:

Author. Accessed from:

http://www.who.int/mental_health/publications/dementia_report_2012/en/

World Health Organization (WHO). 2015. Supporting informal caregivers of people living with dementia. Accessed from:

http://www.who.int/mental_health/neurology/dementia/dementia_thematicbrief_informa I_care.pdf 